\title{
Response to "Overestimation of Chernobyl consequences: calculation of a latent period for tumors with unproven radiation etiology" by $S$. V. Jargin
}

\author{
Victor K. Ivanov
}

Received: 11 July 2009 / Accepted: 26 August 2009 / Published online: 22 September 2009

(C) Springer-Verlag 2009

1. In (Jargin 2009) it is asserted that changes in social conditions and quality of health care in Russia in the 1990s may influence the results of a study published in (Ivanov et al. 2009). However, his assertion is not justified as our study included an internal control group and in thus used information about the studied cohort. In addition to that, we did not examine any temporal changes in morbidity rates, but the relationship between the dose and duration of the latent period.

2. Results of radiation epidemiological analyses performed by members of the Medical Radiological Research Centre are quoted in UNSCEAR publications, which can be considered as an objective appraisal of the quality of the data used in (Ivanov et al. 2009).

3. The international scientific community recognized the increase in thyroid cancer morbidity among those exposed as children to the fallout from the Chernobyl accident as an objective fact. Note that Ivanov et al. (2006) and Heidenreich et al. (1999) examined not only the relative increase of the morbidity but also quantified the relationship between radiation dose and morbidity.

4. The linear non-threshold model of radiation risk is generally accepted. It is used as the basic model for the development of radiation protection standards. One may consider this model as not proven and doubtful, but this consideration should be supported by convincing arguments.

5. The statement in (Jargin 2009) that the analysis described in (Ivanov et al. 2009) is based on a false premise is absolutely unproven.

\section{References}

Heidenreich WF, Kenigsberg J, Jacob P, Buglova E, Goulko G, Paretzke HG, Demidchik EP, Golovneva A (1999) Time trends of thyroid cancer incidence in Belarus after the Chernobyl accident. Radiat Res 151(5):617-625

Ivanov VK, Gorski AI, Tsyb AF, Maksioutov MA, Tumanov KA, Vlasov OK (2006) Radiation-epidemiological studies of thyroid cancer incidence among children and adolescents in the Bryansk oblast of Russia after the Chernobyl accident (1991-2001 follow-up period). Radiat Environ Biophys 45(1):9-16

Ivanov VK, Gorsky AI, Kashcheev VV, Maksioutov MA, Tumanov KA (2009) Latent period in induction of radiogenic solid tumors in the cohort of emergency workers. Radiat Environ Biophys 48(3):247-252

Jargin SV (2009) Overestimation of Chernobyl consequences-calculation of a latent period for tumours with unproven radiation etiology. Radiat Environ Biophys. doi:10.1007/s00411-009-0242-z (this issue)
V. K. Ivanov $(\square)$

Medical Radiological Research Centre,

Russian Academy of Medical Sciences,

4 Korolyov street, 249036 Obninsk, Kaluga Region, Russia

e-mail: nrer@obninsk.com 